\title{
The Impossible Quest - Problems with Diligent Search for Orphan Works
}

\author{
Simone Schroff $\cdot$ Marcella Favale $\cdot$ Aura Bertoni
}

Published online: 11 April 2017

(C) The Author(s) 2017. This article is an open access publication

\begin{abstract}
Digital technologies allow unprecedented preservation and sharing of world-wide cultural heritage. Public and private players are increasingly entering the scene with mass digitisation projects that will make this possible. In Europe, legislative action has been taken to allow cultural institutions to include in their online collections copyright works whose owners are either unknown or non-locatable ("orphan works"). However, according to the Orphan Works Directive, cultural institutions must attempt to locate the owner of a work before using it. This is the so-called "diligent search" requirement. This paper provides an empirical analysis of the conditions under which a diligent search can feasibly be carried out. The United Kingdom, the Netherlands, and Italy, all of which have implemented the Orphan Works Directive, have been selected as case studies. For each jurisdiction, this analysis determines what the requirements for a diligent search to locate copyright holders are, what the authoritative sources and databases to be consulted
\end{abstract}

Research for this article has been carried out as part of EnDOW ("Enhancing access to twentieth century cultural heritage through Distributed Orphan Works clearance"), a project funded by the EU Joint Programming Initiative in Cultural Heritage and Global Change. Details on the project are available at: http://diligentsearch.eu.

\section{S. Schroff $(\bowtie)$}

Research Fellow

IViR Amsterdam, Amsterdam, The Netherlands

e-mail: s.schroff@uva.nl

\section{Favale}

Senior Research Fellow

CIPPM, Bournemouth University, Bournemouth, UK

e-mail: mfavale@bournemouth.ac.uk

\section{A. Bertoni}

Senior Research Fellow

ASK Università Bocconi, Milan, Italy

e-mail: aura.bertoni@unibocconi.it 
are in practice and, most importantly, to what extent these are freely accessible online. In doing so, our analysis provides insights into the two main issues affecting cultural heritage institutions: (1) how much legal certainty does the implementation provide, and (2) what is the practical burden of a diligent search. The analysis reveals that the jurisdictions have given different meanings to the term "diligent". While the UK's extensive guidance makes it unlikely that a search would not be deemed diligent, the search burden is onerous. On the other hand, Italy and especially the Netherlands have a lighter search burden, but in the absence of clear, definite guidance, the likelihood of accidental infringement by failing to meet the diligence standard is greater. In addition, all three jurisdictions have so far failed to take the accessibility of the sources into account, making the searches even more onerous than the numbers suggest at first sight. Therefore, it will be difficult for cultural institutions to clear the rights for their collections while fully complying with the requirements of the legislation. This article concludes that legislative action, official guidelines, or jurisprudence are needed to establish a different legal value of sources for a diligent search, with various degrees of optionality depending on data relevance and accessibility.

Keywords Orphan works · Orphan Works Directive · Mass digitisation - Cultural heritage $\cdot$ Copyright

\section{Introduction}

Europe has been working for decades to open up its invaluable cultural heritage to the world. One key component of this policy is promoting digital access to public collections in libraries, museums, and archives. The heart of this process is the Europeana project, "A European Digital Library for All". ${ }^{1}$ Europeana offers a common gateway to the digital collections of European cultural heritage institutions (CHIs). It was launched in 2008 and has since been supported by acts of the European Parliament, Council, and Commission. ${ }^{2}$ To make archival material available via Europeana though, CHIs have to comply with copyright law as no exceptions are provided for making archives available online. This means that CHIs have to get permission from the right holder before they provide online access to their archives. This poses severe issues in practice because a sizeable share of these materials is considered orphan, meaning that the right holders are unknown or not locatable. Licensing them as required by the law is therefore difficult - if not

\footnotetext{
${ }^{1}$ The Europeana portal is available at: http://www.europeana.eu/portal/ (accessed 9 June 2016). It was conceived within the framework of the i2010 strategy of the Information Society and Media Directorate of the European Commission. The i2010 strategy for an innovative and inclusive European Information Society is available at: http://ec.europa.eu/information_society/doc/factsheets/035-i2010-en.pdf (accessed 14 June 2016).

${ }^{2}$ For example, see the Recommendations by the Commission on Digitisation and Digital Preservation, OJEU L 283/39 (29 October 2011), available at: http://eur-lex.europa.eu/LexUriServ/LexUriServ.do?uri= OJ:L:2011:283:0039:0045:EN:PDF (accessed 9 June 2016).
} 
impossible. The result is that CHIs that make these works available face the threat of copyright infringement action.

It is in this context that the Orphan Works Directive (OWD) was adopted in 2012. ${ }^{3}$ The OWD allows cultural heritage institutions to digitise and make available online these orphan works in their collections as part of a mandatory copyright exception, once a diligent search has been carried out. ${ }^{4}$ In other words, the OWD provides CHIs with a way to make their orphan works accessible online by providing them with the legal certainty that they will not be liable for copyright infringement as long as they have complied with the diligent search requirement. On the surface, therefore, the OWD addresses the core issue: the lack of legal certainty about using orphan works. However, this only works in practice if a CHI can clearly identify what it has to do when carrying out the diligent search. Yet at this crucial point the Directive is based on the principle of minimum harmonisation, leaving substantial leeway to the Member States.

This article examines the nature of a diligent search in practice, given that the requirements have not been fully harmonised. It analyses the diligent search requirements in three EU Member States - the Netherlands, the UK, and Italy to assess the conditions under which a diligent search must be carried out. The first part focuses on how Member States have implemented the requirement from the point of view of legal certainty. In other words, to what extent have the Member States clarified which sources a CHI has to consult for a search to be deemed "diligent"? To answer this question, the emphasis is on the kind of guidance the regulators provide to the CHIs. By basing the discussion on legal certainty, this article contributes to the debate by highlighting how CHIs perceive the environment they face as they calculate the risks involved in their mass digitising efforts when standard licensing is not possible. In the second part, attention then shifts to the price of legal certainty: the burden of the search. The OWD is only an effective instrument if its requirements can be met by CHIs in practice. In the context of the diligent search, this refers mainly to the resources needed to carry out the search, in particular the number of sources that needs to be consulted and the extent to which they are easily accessible. This article relies on empirical evidence collected from the three jurisdictions to assess this search burden, providing a real-life image for the first time. The article concludes that not only is legal certainty still an issue due to a lack of definite guidance, but also that the search burden is too heavy for CHIs with limited resources. This renders the OWD ineffective for large-scale digitisation efforts. The conclusion will identify policy aspects that could be amended to streamline the process.

\footnotetext{
${ }^{3}$ Directive 2012/28/EU of the European Parliament and of the Council of 25 October 2012 on certain permitted uses of orphan works. OJ L 299, pp. 5-12 (27 October 2012). Hereinafter, the Orphan Works Directive, or OWD, or the Directive.

4 Article 3.1.
} 


\section{The Orphan Works Directive: The Meaning of "Diligent"?}

The OWD adopts a minimum harmonisation approach to the diligent search requirement. In particular, it focuses on the underlying strategy of the search rather than the particular items that need to be searched. Article 3(1) OWD states that "a diligent search is carried out in good faith in respect of each work or other protected subject-matter, by consulting the appropriate sources for the category of works and other protected subject-matter in question". ${ }^{5}$ In other words, a CHI has to make an honest effort to identify and locate the right holder for each copyright and neighbouring right aspect relevant to the archival item it seeks to make available online. However, while this seems to be clear enough, it does pose some significant stumbling blocks in practice.

\subsection{What Do We Need to Search?}

A diligent search requires that an effort is made to find the author and/or right holder for each work affected in a specific archival item. To do this, relevant sources that may provide this information, in particular databases, have to be consulted. The Directive states: "The sources that are appropriate for each category of works or phonogram in question shall be determined by each Member State, in consultation with rightholders and users, and shall include at least the relevant sources listed in the Annex." ${ }^{6}$ The Directive therefore only sets a minimum standard by defining certain categories of works. A closer look reveals what this minimum standard means. The sources in the Annex can be broadly divided into two categories. First, there are catalogues and registries. Most notably, the type of registries and catalogues named are those that are most likely to be the most comprehensive in practice, e.g. legal deposits and those used to assign vital commercial information, such as the ISBN for books and equivalents. The second group are the sources identifying the right holder. The approach here essentially combines the effects of copyright law and industry practice. For example, the sources touching on literary works include both the author and the publisher. Similarly, the sources regarding musical works cover the composer, the lyricist, and the publisher, as well as the producer. It is thus clear that the legislative intent is to compile a list that covers all authors and right holders relevant to a particular type of work. However, it is up to the Member States to apply this to their national organisational landscape. They must determine which particular sources have to be consulted for each type of work covered by this Directive. In this context, leaving it to the Member States is in line with the principle of subsidiarity enshrined in the treaties. ${ }^{7}$ In particular, copyright and neighbouring rights have not been fully harmonised at EU level. The organisational landscape, such as author associations and collective management entities, varies even more. It would therefore have been too complex to list all the sources at EU level. Therefore, the Annex list represents a case of minimum harmonisation and a difficult compromise between the need to build a common European framework, the lack of legal harmonisation, and the recognition of national differences within a given sector.

\footnotetext{
${ }^{5}$ Orphan Works Directive, Art. 3(1).

${ }^{6}$ Orphan Works Directive, Art. 3(2).

7 TEU, Art. 5.
} 
When implementing the provisions, Member States have to balance legal certainty with flexibility. The principle of legal certainty is best served if the list of sources is as specific as possible. A precise list offers the CHI seeking to use the OWD exception a clear guide as to when a search is diligent and when it is not. These concerns, however, must be weighed against the cost in terms of flexibility: the organisational landscape is not static. Precise lists are only useful in practice if they are regularly updated to keep up with changes. On the other hand, while an open-ended list limits the need for future amendments in the light of industry changes, it also carries the pronounced risk that important institutions are missed. In this case, the $\mathrm{CHI}$ faces significant risks as the whole diligent search may be deemed void, exposing it to infringement claims.

In the examined jurisdictions, the details on what is a legally valid diligent search vary greatly, mostly because of the presence or absence of soft-law regulation on the matter. The UK has implemented the Annex under Schedule ZA1 which provides for an illustrative list of sources to be consulted. While there is no minimum requirement established by statutory law on what constitutes a diligent search, the UK's Intellectual Property Office (IPO) has issued detailed guidelines on this complex matter. Most notably, this includes a specific list of sources to be consulted for each type of work in the form of a check list. The list is extensive and in fact contains nearly all organisations that have some link to rights ownership. There is no weighting attached to the individual sources or any indication of importance. It reflects an understanding of "diligent" as searching any kind of source that may contain information. Having said this, the last entry is open-ended: it therefore leaves the option open that further sources may be deemed relevant for the search to be diligent. Overall, the IPO guidelines can help both the prospective applicant for a licence for an orphan work and the cultural institution seeking to benefit from the exception. It reduces the risk of accidental infringement significantly, albeit not entirely, by providing a large number of specific sources.

In comparison to the UK, Italy provides significantly less guidance due to the administrative process involved. Italy has implemented the Annex directly in the Copyright Act. ${ }^{8}$ The list proposed by Art. $69^{\text {septies }}$ is merely illustrative, which means that uncertainty remains about the legal validity of a search carried out according to the suggestions of the law. ${ }^{9}$ However, the Ministry of Culture has vouched to identify additional sources of information for each category of works or phonograms by decree. It has established a Technical Negotiation Unit on Orphan Works within its Directorate-General for libraries and cultural institutions (DGBIC -Direzione generale biblioteche e istituti culturali). The Directorate General is mandated to produce guidelines on a diligent search for the different categories of works. ${ }^{10}$ However, this process has not been completed yet even though two years have passed since the Directive took effect. Instead, in Italy the only available

\footnotetext{
${ }^{8}$ Law No. 633/1941, Art. $69^{\text {septies }}$.

9 Leva (2015), p. 11.

10 The technical negotiation unit was established on 17 November 2015 by the Ministry of Culture. Decreto Direttoriale of 17 November 2015, http://www.librari.beniculturali.it/opencms/export/sites/ dgbid/it/documenti/Normativa/DecretoTavolotecnicoConcertazione17-11-2015.pdf (accessed 27 May 2016). See also DGBIC (Direzione Generale Biblioteche e Istituti Culturali) report at: http://www.librari. beniculturali.it/opencms/opencms/it/Opere_Orfane (accessed 27 May 2016).
} 
guidance on the sources to clear the rights in orphan works consists of a list of "appropriate sources" on the Ministry's website, which is continuously updated. ${ }^{11}$ The Italian approach, therefore, while displaying the intention of providing certainty to CHIs, is significantly delayed by the bureaucratic process. At this point, therefore, the CHIs only have indicative advice, falling short of legal certainty in respect of what sources need to be consulted to make a search diligent.

In contrast to the UK and Italy, the Netherlands has taken a consciously hands-off approach. The letter of the Directive has been transposed into national law. In fact, the Government Decree ${ }^{12}$ by which diligent search sources were transposed into Dutch legislation is essentially a translation of the OWD Annex. For example, it refers to the "databases of publishers and authors" without naming any specific institution. Indeed, the only specific source mentioned is the catalogue of the Royal Library, and in the case of audio-visual works, the archive of Beeld en Geluid. ${ }^{13}$ Overall, the terminology used is unspecific and open-ended. Besides, little effort is made to complement it with specific sources. Instead, it is up to the CHI to decide what to consult, and therefore crucially relies on in-house expertise. Having said this, however, it is not clear if this approach has always been envisioned. On the one hand, a homepage with further information has been mentioned in the parliamentary debate, but this has not materialised yet. ${ }^{14}$ At the same time though, any advice was never intended to be exhaustive. Instead, it was always the aim that the institution itself decides which sources are relevant for a particular work. ${ }^{15}$ From this point of view, the very general list could be read as meeting the cultural heritage institutions' preference for redelijkheid (reasonableness) and billijkheid (equity) which they requested in the consultation process. ${ }^{16}$ The absence of official guidance means that CHIs lack certainty about what "diligence" actually means in practice. Therefore, it seems that the diligent search implementation in the Netherlands is focused on legal compliance with European commitments rather than creating legal certainty around a workable diligent search provision. The practical effect may be mitigated though by the existing Extended Collective Management systems in force. This is most clearly seen in Dutch cultural heritage institutions' pushing for and relying on ECLstyle solutions rather than the OWD,${ }^{17}$ which are seen as the better option to deal with orphan works.

The evidence from the three jurisdictions examined here reveals that each has given different emphasis to legal certainty. While the UK provides for long lists of specific sources and therefore reaches a high degree of legal certainty, the

\footnotetext{
11 The list is available at: http://www.librari.beniculturali.it/opencms/opencms/it/Opere_Orfane/pagina_ 0001.html (accessed 27 May 2016).

12 Besluit zorgvuldig onderzoek verweesde werken, available at: http://wetten.overheid.nl/ BWBR0035690/2014-10-29 (accessed 9 May 2016).

13 The decree does not actually name Beeld en Geluid but, given its reference to the media law, it is this archive in practice. It does require some research though to make this link.

14 Nota naar aanleiding van het verslag Kamerstukken II 2013/14, 33892, 6, p. 7.

15 Ibid.

16 See for example: Beunen (2011), pp. 2 and 5-6; Kraai (2011), p. 1; van Nispen (2011), p. 2.

17 Nota naar aanleiding van het verslag Kamerstukken II 2013/14, 33892, 6, p. 12. The Royal Library, for example, relies on ECL schemes rather than the orphan works exception.
} 
Netherlands has consciously preferred flexibility instead. Italy is a half-way house between the two extreme positions, although this is more by accident than by design. However, all three countries are essentially taking an open-ended approach. As none of the jurisdictions examined here provides a list of sources that covers everything required for the search be considered diligent beyond any doubt, CHIs need to be able, at least to some extent, to identify which organisations may hold relevant information.

\subsection{Legal Certainty and Outsourcing}

The previous section has demonstrated that an understanding of copyright law and the related organisational landscape that manages rights in practice is a key prerequisite for a successful diligent search. This kind of knowledge should probably not be presumed, especially in the case of smaller CHIs. The issue, however, is even more pressing in practice as the OWD does not limit searches to a single Member State. Instead, it envisages three scenarios in which a CHI would have to carry out its diligent search in other EU Member States in addition to its own. As a general rule, a diligent search has to be carried out in the Member State where the first publication or communication to the public (broadcast) has occurred. ${ }^{18}$ There are only three deviations from this principle. First, the headquarters or habitual residence of the producer of a film overrides the publication/broadcast principle. ${ }^{19}$ Second, if the work has not yet been made available to the public, jurisdiction is determined by the location of the institution relying on the exception. ${ }^{20}$ More importantly though, when there is evidence that relevant information may be found in another Member State, the foreign sources must be consulted as well. ${ }^{21}$ These requirements pose very practical challenges in terms of a diligent search and legal certainty.

In the absence of legal guidance, the need to search in foreign jurisdictions requires significant legal expertise. Copyright works and their ownership are only partially harmonised under current EU law, so determining who the author and/or right holder is can be complex. As Angelopoulos has aptly demonstrated, the rules on authorship and ownership continue to vary ${ }^{22}$ : a qualifying author may hold rights in one Member State but not another. In addition, there are neighbouring rights that are not protected in all Member States and therefore might be largely unknown beyond a jurisdiction's borders. One example here is the German neighbouring right for the organiser of a performance. ${ }^{23}$ In other words, the lack of copyright harmonisation poses challenges in respect of identifying what works need to be cleared in the first place and who their right holders will be. It cannot be readily presumed that CHIs have access to this kind of detailed legal and practical knowledge. As a result, the quality of their diligent search may be negatively

\footnotetext{
18 Orphan Works Directive, Art. 3(3).

19 Orphan Works Directive, Art. 3(3).

${ }^{20}$ Orphan Works Directive, Art. 3(3).

21 Orphan Works Directive, Art. 3(4).

22 Angelopoulos (2012).

${ }^{23}$ Copyright Act (Urheberrechtsgesetz), Sec. 81.
} 
affected when other jurisdictions have to be consulted. This in turn impacts on the legal certainty that the OWD as a whole provides: the risk of a search being deemed "not diligent" increases as key sources are missed. The less guidance a Member State provides on the required sources for a search to be considered diligent, the more pronounced the issue becomes.

Given the open-ended nature of source lists to be consulted and the limited guidance in Italy and especially in the Netherlands, it will be very challenging for a $\mathrm{CHI}$ to identify the necessary sources consistently. One way to alleviate this pressure would be outsourcing the diligent search, so that it is carried out not by the $\mathrm{CHI}$ itself but instead by a third actor that has the required expertise. In general, the OWD restricts its coverage to cultural heritage institutions but it does not have binding provisions on who carries out the diligent search. Indeed, Recital 13 of the OWD explicitly permits a delegation of the task: "Member States should be permitted to provide that such diligent search may be carried out by the organisations referred to in this Directive or by other organisations. Such other organisations may charge for the service of carrying out a diligent search." ${ }^{24}$ This means that outsourcing of the diligent search task has always been envisioned by the legislature. ${ }^{25}$

Most interestingly though, none of the Member States examined in this paper has actually implemented this option in the way provided for by the Directive. In fact, neither the Italian nor the Dutch implementation covers this issue at all. In the absence of any legal discussion of this point, it is arguably possible for CHIs to outsource the diligent search. However, there is significantly less legal certainty in this approach than there would have been if the option was either clearly permitted or denied. On the other hand, the UK goes a lot further than the OWD: it permits both cultural heritage institutions and any legal or physical person willing to license a potentially orphan work to carry out the search. While this sounds contrary to the Directive at first glance, we argue that it is not. The UK has opted not only to implement the OWD but also to complement it with a general licensing scheme that goes beyond CHIs. The result is a path for the use of orphan works by any actor wishing to do so if he completes a diligent search. This broad approach logically necessitates that the search can be carried out by anyone, including non-CHIs. In other words, while the Recital was implemented, it is a lot broader in practice than the OWD envisaged.

The lack of guidance and/or use of open lists that Member States provide to CHIs carrying out a diligent search have the most pronounced impact on cross-jurisdictional sources. Copyright has not been fully harmonised at EU level, allowing for major variations between Member States. In the context of limited resources and expertise, CHIs will not be easily able to reliably assess the ownership, authorship and rights management patterns that are the key to a successful diligent search. In fact, the less guidance is provided to the $\mathrm{CHI}$, the more likely it becomes that key sources are missed. This in turn means that CHIs cannot be certain that they are shielded from infringement claims, negatively affecting the legal certainty that the OWD seeks to provide in the first place.

\footnotetext{
24 Orphan Works Directive, Recital 13.

25 It should be noted here that final compliance with the diligent search requirement remains the responsibility of the organisation benefitting from the exception. In the context examined here, this refers to the $\mathrm{CHI}$.
} 


\section{The Cost of a Diligent Search}

The three jurisdictions examined in this paper have struck different balances between legal certainty and flexibility. This now raises the second question: what is the price of the degree of legal certainty offered? To answer this question, it is necessary to simulate a diligent search. Based on an in-depth understanding of the law in force, including both hard and soft law instruments, as well as the organisational landscape present in the different countries, we have compiled a data set of institutions that manage directories of potential right holders and copyright works. These databases arguably need to be consulted (in the case of the UK, they must be consulted) in order for a search to be deemed diligent. In doing so, we provide a realistic image of what a $\mathrm{CHI}$ has to do in practice to meet the legal requirements of acting in good faith and being diligent. As the following graph shows, the number of sources to be consulted varies extensively.

\subsection{Quantifying the Meaning of "Diligence"}

\section{$\mathrm{Number}$ of Sources}

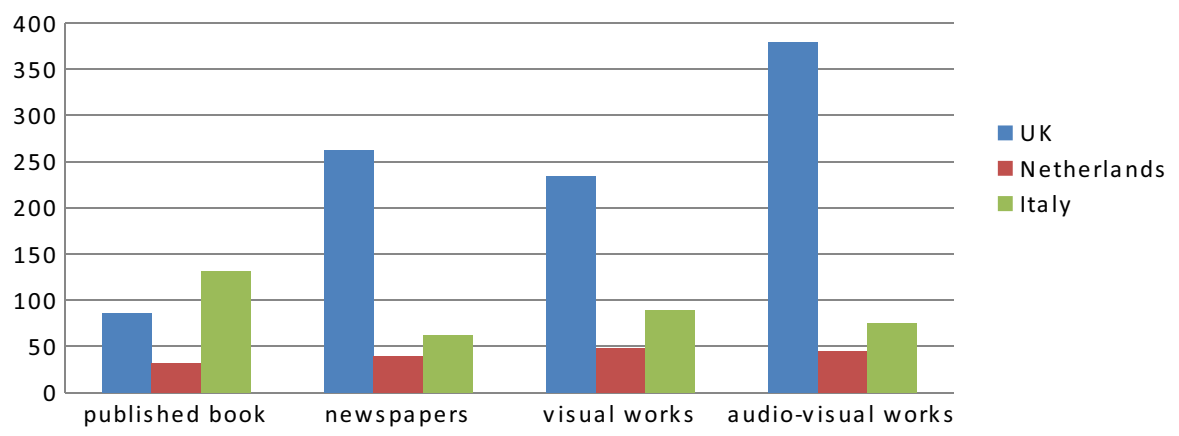

As expected, the number of sources to be consulted varies significantly across the types of works and the three jurisdictions examined here. In general, published books have the fewest relevant sources, followed by newspapers/magazines, visual works and finally audio-visual works. This order is not surprising, given that the number of potential right holders increases with each category. ${ }^{26}$ Two things are notable: first, the overall numbers indicate that the diligent search requirement is very burdensome although the extent varies across jurisdictions. For example, to clear a newspaper article, a UK CHI would have to search 234 sources. In Italy it would be 89 sources, followed by the Netherlands with 48 . These numbers are so high that it is very unlikely that a CHI would have the resources to clear more than a few works at best without some kind of automation. However, this is not available or even planned in the examined jurisdictions.

\footnotetext{
${ }^{26}$ It should be noted here that the OWD only includes visual works that form part of a literary work. As a result, the sources here also include those relevant to the overall work, be it a published book or a magazine.
} 
Second, there seems to be a link between the number of sources and the guidance provided by regulators. In the UK, with the exception of published books, more sources are considered relevant than in the other two jurisdiction (86 for published books, 263 for newspapers and magazines, 234 for visual works, and 379 for audiovisual works). This is followed by Italy (131, 62, 89 and 75, respectively) and then the Netherlands $(32,39,48,45$ sources, respectively). It is interesting to see that the country with the most detailed guidance, the UK, has the most sources, followed by the semi-guidance (Italy) and finally the jurisdiction that provides no additional information (the Netherlands). This indicates the most likely impact of the regulators' response to the OWD Annex: the regulators tend to be over-inclusive. In particular, the UK's numbers are not only higher, but in fact multiples of those for the other two jurisdictions examined here. For example, in the case of audio-visual works, the UK's IPO lists 379 sources and therefore five times more compared to Italy (75 sources) and more than eight times as many as the Netherlands (45 sources). It thus seems that the IPO lists are essentially a list of all organisations in the sector rather than a selection of those sources most likely to yield information. This list is essentially over-inclusive to the point where "diligent search" is a synonym for "exhaustive search".

The price of legal certainty therefore seems to be high, making the search very resource-intensive. The numbers indicate that the more a Member State has opted for legal certainty at the expense of flexibility, the larger the number of sources that needs to be consulted. Providing guidance on what searches need to be performed in effect does not lead to a hierarchy of the most important sources. Instead, it is a list of possibly relevant sources, making them over-inclusive. However, the number of sources to be consulted alone is an incomplete indicator of how burdensome a search is in practice.

\subsection{The Qualitative Meaning of "Diligent": The Accessibility of Sources}

The practical burden of the diligent search requirement crucially depends on two factors. First, there is the number of sources that must be consulted as discussed in the previous section. The more sources that need to be searched for each work type, the higher the investment in terms of time and resources by the CHI to clear a work. Second, the online accessibility - or here more precisely searchable nature - of the sources is important. It is less resource-intensive to search online compared to having to visit an institution to search the catalogue. As a result, the higher the proportion of sources that are not freely and fully accessible online, the more burdensome a diligent search is in practice. It is therefore crucial to ascertain to what extent sources are accessible. To this end, this research has collected an empirical data set in which each source identified as relevant was classified in terms of the access restrictions under which it operates, distinguishing between those fully and freely accessible online and those that are not. The latter was then further divided into: (1) paying access online; (2) partially accessible online; (3) will be accessible online in the future; and (4) free access on site only. The analysis of these data will provide crucial insights into the viability of the diligent search exception as provided by the OWD, and the potential drawbacks and pitfalls of this route. We will now proceed to describe our findings. 
First of all, one particular type of required source deserves attention: the orphan works databases. To prevent the duplication of efforts, the OWD provides for the mutual recognition of the status of orphan works. In other words, once a work has been declared orphan in one Member State, it is considered orphan in all Member States until a right holder makes a valid claim. ${ }^{27}$ To facilitate this, cultural institutions are asked to keep records of their diligent searches, and the results of such searches are due to be inserted in a single online database for the European Union to be made available to the public at large in a transparent manner. ${ }^{28}$ To this end, the OWD calls for an EU-wide database to be created at the EUIPO, ${ }^{29}$ which receives and consolidates information from all Member States. In addition, Member States are free to develop their own databases in addition to the one managed by the EUIPO. ${ }^{30}$ This particular source, the EUIPO Database - or where available, a national database - is therefore mandatory in all jurisdictions.

However, the development of these databases has been slow in practice. The EUIPO database is already operational but contains very few entries: little more than 2000 entries at the time of writing. ${ }^{31}$ This lack of uptake is even more pronounced at the national level. While the establishment of national databases is not required by the Directive, all three jurisdictions originally planned to have a national database as well to prevent duplication domestically. However, the outcomes of these plans are mixed at best. The UK has its own database which contains about 350 entries. ${ }^{32}$ The overall number of works is therefore low but at least it is operational. It should also be noted though that this database forms part of a broader licensing scheme which also covers orphan works that are subject to the OWD, for example stand-alone photographs. On the other hand, the databases planned in the Netherlands and Italy have not been developed yet. In the Netherlands, it is known that the results of a diligent search have to be reported by the CHI to the Dutch Minister of Education, Culture and Science, and that the Dutch orphan works database is to be maintained by the Rijksdienst Cultureel Erfgoed. The government will then transmit the information to EUIPO. ${ }^{33}$ While the transfer to EUIPO is functional, and indeed most works in the database are from Dutch CHIs, the national database has not made any progress. Similarly, the Italian orphan works database is also not operational yet. ${ }^{34}$ Once the national database is created, beneficiary organisations need to communicate the results of diligent searches to the

\footnotetext{
27 Orphan Works Directive, Art. 4.

28 Orphan Works Directive, Recital 16.

29 Orphan Works Directive, Art. 6(5) and (6).

30 Orphan Works Directive, Art. 3(5).

31 On 9 June 2016 the EUIPO database contained 1,726 entries. See https://euipo.europa.eu/ orphanworks/\#search/basic/all (accessed 9 June 2016).

${ }^{32}$ There were 351 entries on 9 June 2016. See https://www.orphanworkslicensing.service.gov.uk/viewregister (accessed 9 June 2016).

33 Art. $16 \mathrm{p}(5)$ Aw.

${ }^{34}$ Decreto Direttoriale del 17.11.2015, http://www.librari.beniculturali.it/opencms/export/sites/dgbid/it/ documenti/Normativa/DecretoTavolotecnicoConcertazione17-11-2015.pdf (accessed 27 May 2016). See also DGBIC (Direzione Generale Biblioteche e Istituti Culturali) report at http://www.librari. beniculturali.it/opencms/opencms/it/Opere_Orfane (accessed 27 May 2016).
} 
Directorate-General for libraries and cultural institutions (DGBIC - Direzione generale biblioteche e istituti culturali) at the Ministry of Culture. The DGBIC has to transmit the information to the European database at EUIPO. However, the national database at the heart of this has not been created yet, leading to confusion. In particular, it is not clear whether national registration is a precondition for European registration. As a result, no Italian cultural institution appears in the EUIPO database at the moment due to fear of infringing national legislation by a direct registration at EU level.

The current state of the orphan works databases at national and EU level severely limits the effectiveness of these sources. On the one hand, the UK has a working database but it is over-inclusive by covering works beyond the scope of the Directive. As a result, not all of them benefit from the mutual recognition of their status as orphan. On the other hand, the Netherlands and Italy have no databases yet. This means that one of the main sources is simply not available. In Italy's case, this also impacts on the effectiveness of the EUIPO-managed database as the hyperlink to the Italian jurisdiction on the EUIPO website is not working. However, not all required sources are subject to these start-up issues.

\subsubsection{Overall Accessibility}

A first look at the data reveals that the UK has the highest percentage of sources that are freely accessible online (70\% of all sources). However, $70 \%$ is still problematic because it also means that $30 \%$ of listed sources require additional effort of some kind. Of these, only $2 \%$ offer free on-site access. By contrast, direct contact is required - either by email or mail - for $22 \%$ of the sources, making the process more time and resource-consuming. The picture is even less promising for Italy and the Netherlands. Here, only about half of the sources can be fully accessed online (Italy: 56\%; Netherlands: 54\%) (Table 1).

It should be noted that the largest, most comprehensive databases in the Netherlands do not fall into this category. In fact, $41 \%$ of all sources in the Netherlands are not directly accessible at all. In particular, the large Collective Management Organisations (CMOs) with the broadest membership fall into this group. The only exceptions to this pattern are two CMOs: Pictoright ${ }^{35}$ (art works) and BUMA/STEMRA (musical works). For all other large databases, direct contact is required. As the guidelines for the diligent search report have not yet been published, it is not clear if the contact has to be in writing, making it very resource-intensive. The lack of a paper trail proving a search result may require this in practice. Instead, smaller organisations have freely accessible databases.

Italy has a very varied accessibility pattern in practice: $44 \%$ cannot be accessed freely online. This is comparable to the Netherlands. However, the restrictions on the remaining databases are more varied: only $23 \%$ of sources

\footnotetext{
${ }^{35}$ A list of members is available here: https://mijn.pictoright.nl/user/Content_LedenlijstStart.cfm (accessed 6 June 16). However, it is likely that this is incomplete due to tensions between artists and commercial intermediaries.
} 
Table 1 Accessibility of sources in the UK, Italy and the Netherlands

\begin{tabular}{|c|c|c|c|c|c|c|c|c|}
\hline \multirow{2}{*}{$\begin{array}{l}\text { Source } \\
\text { accessibility }\end{array}$} & \multicolumn{2}{|l|}{ UK } & \multicolumn{2}{|l|}{ Italy } & \multicolumn{2}{|c|}{ Netherlands } & \multirow{2}{*}{$\begin{array}{l}\text { Total } \\
\text { (number) }\end{array}$} & \multirow{2}{*}{$\begin{array}{l}\text { Total (in } \\
\text { percent) }\end{array}$} \\
\hline & Number & Percent & Number & Percent & Number & Percent & & \\
\hline $\begin{array}{l}\text { Number of } \\
\text { sources }\end{array}$ & 210 & & 357 & & 87 & & 654 & \\
\hline $\begin{array}{l}\text { Freely accessibly } \\
\text { online }\end{array}$ & 147 & 70 & 200 & 56 & 47 & 54 & 394 & 60 \\
\hline $\begin{array}{l}\text { Not accessible } \\
\text { online }\end{array}$ & 63 & 30 & 157 & 44 & 40 & 46 & 260 & 40 \\
\hline $\begin{array}{l}\text { Require direct } \\
\text { contact }\end{array}$ & 46 & 22 & 82 & 23 & 36 & 41 & 164 & 25 \\
\hline $\begin{array}{l}\text { Paying access } \\
\text { online }\end{array}$ & 9 & 4 & 10 & 3 & 2 & 2 & 21 & 3 \\
\hline $\begin{array}{l}\text { Free access on } \\
\text { site }\end{array}$ & 5 & 2 & 24 & 7 & 0 & 0 & 29 & 4 \\
\hline $\begin{array}{l}\text { Partial access } \\
\text { online }\end{array}$ & 3 & 2 & 33 & 9 & 1 & 1 & 37 & 6 \\
\hline $\begin{array}{l}\text { Will be } \\
\text { accessible in } \\
\text { the future }\end{array}$ & 0 & 0 & 8 & 2 & 1 & 1 & 9 & 1 \\
\hline
\end{tabular}

require direct contact which is the most onerous kind of search. Instead, Italy has comparatively many sources that are accessible online subject to restrictions. At least, $7 \%$ of sources can be searched on-site. Most notably, the primary source identified by the law is the Registro Pubblico Generale delle Opere Protette (General Public Registry of Protected Works) established by the Ministry of Culture, whose consultation is recommended for almost all categories of work, ${ }^{36}$ which falls into this category. ${ }^{37}$ This means that any diligent search requires a visit to this institution. However, the real difficulty is posed by another category of access: partial online access (9\% of sources identified). These sources require an understanding of what is and is not online. Failure to do so can invalidate a diligent search because a source was not fully searched. For example, if a CHI fails to consult the offline part of the catalogue and misses important information as a result, its search was not diligent as prescribed by the law. Importantly, all legal deposits and the major Italian libraries have not yet completed the digitisation of their catalogues and therefore fall into this group.

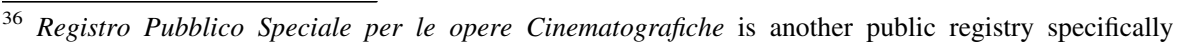
designed for audio-visual works. Like the general public registry, this is only available on-site. This registry is located at the Cinema Section of the Italian CMO SIAE (Società Italiana degli Autori ed Editori), which retains the volumes containing all records made from 1938 to the present, divided into films, short films, and news.

${ }^{37}$ This registry is located at the Italian National Library in Rome (Biblioteca Nazionale Centrale di Roma, V.le Castro Pretorio, 105 - 00185 Roma).
} 


\subsubsection{Accessibility by Type of Work}

As the previous section has shown, all three jurisdictions examined in this paper require sources to be consulted that are not freely accessible online. Many of these can in fact only be accessed on site or require direct contact with the organisation managing them. This raises the cost of a diligent search in practice. However, the data presented so far are aggregate numbers. The diligent search requirement is based on searching the relevant sources by the nature of the source; for example, a published book requires the consultation of different sources compared to an audiovisual work. As a result, it may be possible that some types of works are easier to clear than others. To clarify if this is indeed the case, we have broken down the sources according to the type of work they touch upon and then compared them within the jurisdictions.

\section{Accessibility of Sources by Work Type} (UK)

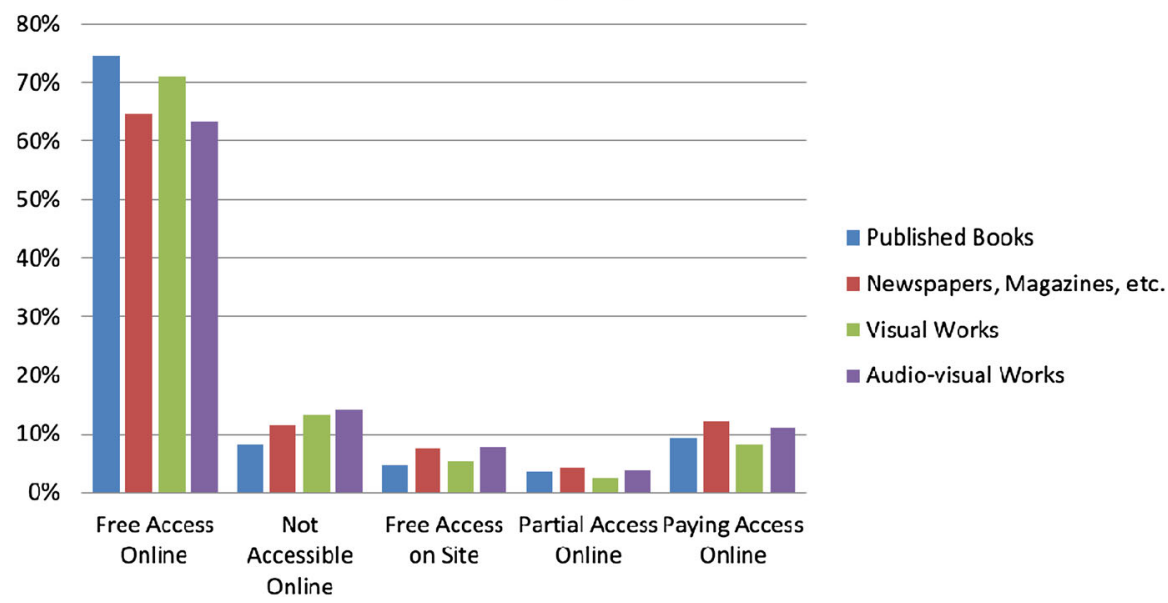

In the UK, the percentages are comparatively stable across the types of works. All four categories examined here, published books, newspapers, visual works and audio-visual works, have similarly high proportions of freely accessible sources. These range from $74 \%$ for published books to $63 \%$ for audio-visual works. ${ }^{38}$ The differences are also minor for the other, more restricted categories of online access. "Paying Access Online" such as subscriptions range around $10 \%$, published books have $9 \%$, magazines $12 \%$, art works $8 \%$, and audio-visual works $11 \%$. It is interesting to see, however, that partial online access does not really play a role. All types of works examined here have less than $5 \%$ of sources that are available online but not in their entirety. ${ }^{39}$ On the other hand, the numbers of sources that cannot be accessed online or only on-site are low

\footnotetext{
38 Newspapers and magazines: $65 \%$; art works: $71 \%$.

39 Published books: $3 \%$; magazines: $4 \%$; art works: $3 \%$; and audio-visual works: $4 \%$.
} 
and also comparable across types of works. Audio-visual works have the largest share here, namely $14 \%$, followed by art works (13\%), magazines $(11 \%)$, and finally published books $(8 \%)$. The percentages are even lower for sources that can be accessed freely on site but not online. ${ }^{40}$ This means overall that the accessibility of sources in the UK does not systematically vary across types of works to any significant extent. Instead, the likelihood that a source is freely accessible online is the same for all four categories, as is the case with the other accessibility classifications.

\section{Accessibility of Sources by Work Type (Netherlands)}

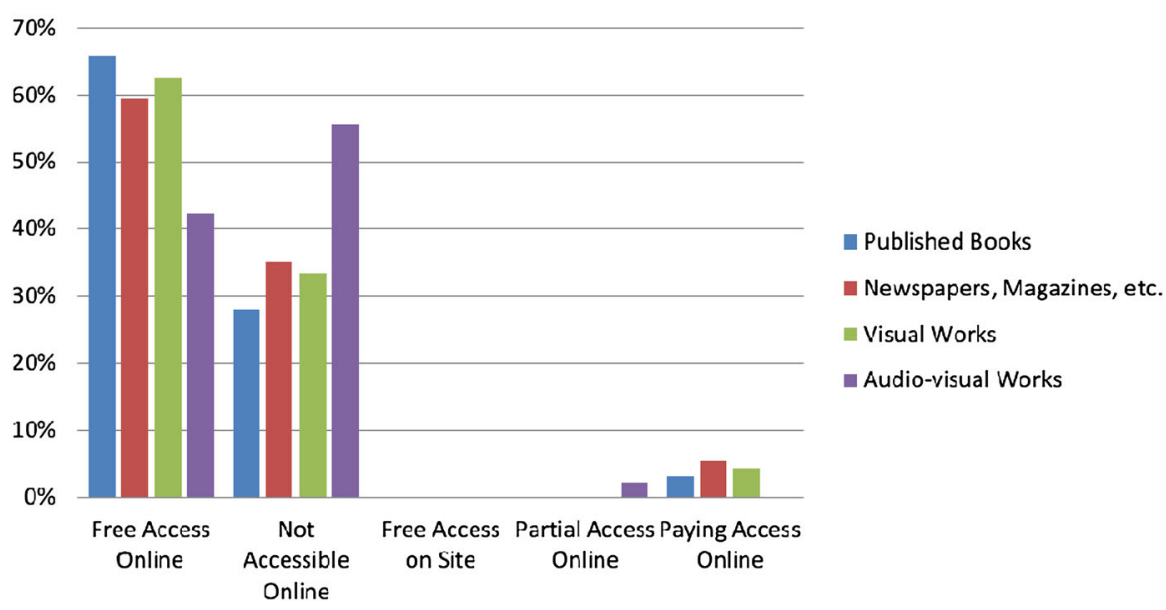

The UK pattern differs significantly from the Dutch one. Here, accessibility varies significantly between work types. Looking at the freely accessible sources first, it is clear that published books, visual works, and magazines have similar proportions of sources that can be freely accessed (66, 63, and 55\%, respectively). However, the proportion is significantly smaller for audio-visual works: here only $42 \%$ and therefore not even half are freely accessible online. Instead, most sources are simply not accessible online and this varies across work types. Restricted access is indeed highest for audio-visual works $(56 \%)$, followed by the significantly smaller numbers of published books (28\%), art works (33\%), and magazines (35\%). It should be noted at this stage that partial online access only plays a minor role in the Netherlands, irrespective of the work type. Free access on site is not relevant at all while "Paying Access Online" stays at or below 5\% for all work types and is de facto absent for audio-visual works. ${ }^{41}$ Partial online access is therefore not a determinative feature of the environment. In other words, clearing audio-visual works is more complex in the Netherlands than the other three groups because more

\footnotetext{
${ }^{40}$ Published books: 5\%; magazines: $8 \%$; art works: 5\%; and audio-visual works $8 \%$.

41 Published books: 3\%; newspapers: 5\%; visual works: 4\%; audio-visual works: $0 \%$.
} 
than half of the relevant sources are not freely accessible and indeed require the $\mathrm{CHI}$ to either visit or contact the relevant organisation directly.

\section{Accessibility of Sources by Work Type (Italy)}

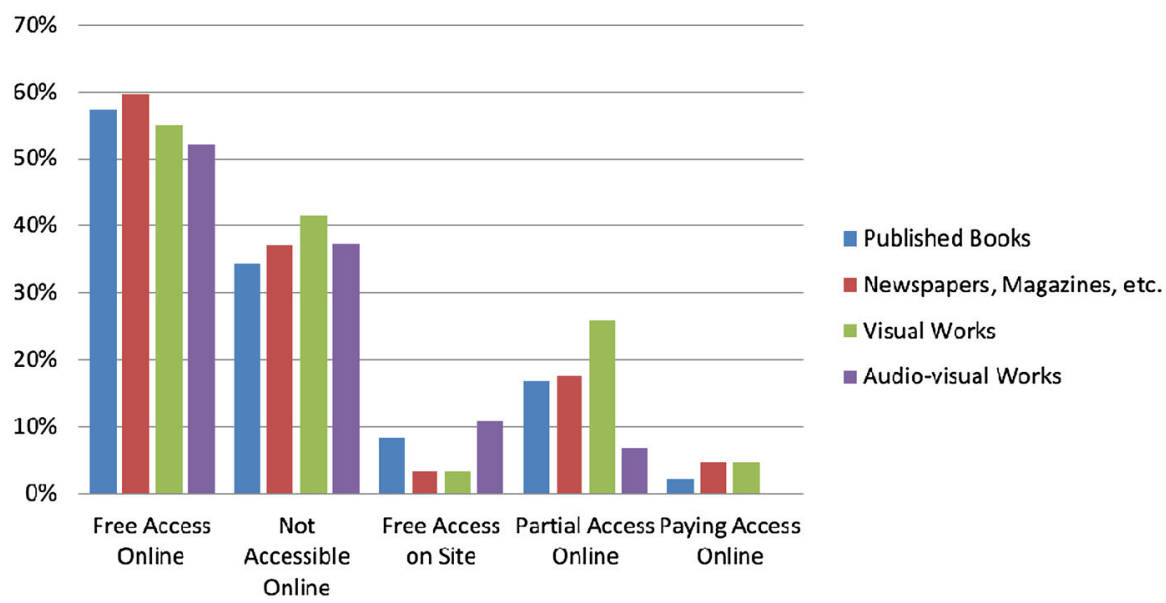

Italy has a different pattern of accessibility across work types from the other two jurisdictions examined here because partially accessible sources play a larger role. First, when it comes to the sources that are freely accessible online, there is not much difference across work types. They generally range between 52\% (audiovisual works) and $60 \%$ for magazines and newspapers. ${ }^{42}$ It is interesting that magazines have the highest percentage, even if the difference to published books $(57 \%)$ is only marginal. At the other end of the spectrum, visual works have the highest share of sources that cannot be accessed directly at all and therefore require direct contact with the institution; $42 \%$ of sources fall into this category. The percentages for the other types of works are similarly high with $37 \%$ for audiovisual works and magazines, and 34\% for published books.

However, there are significant differences between work types when it comes to sources that are available online but restricted. In general, paying for access, such as by subscription, is only a small percentage: $5 \%$ for newspapers, $4 \%$ for visual works, and $2 \%$ for published books, and is indeed not relevant at all for audio-visual works. However, sources that are only partially searchable online are very relevant to a diligent search. Most notably, 26\% of the sources required to search for visual works are only partially accessible. This is followed by magazines $(18 \%)$, published books $(17 \%)$, and finally audio-visual works $(7 \%)$. This is very significant because partially accessible sources can be potentially very difficult to manage in practice. They require that the searching party fully understands what is available online and what is not. A lack of clarity could mean that the CHI thought it searched the whole

\footnotetext{
$\overline{42}$ Visual works: $55 \%$; published books: $57 \%$.
} 
catalogue when in fact it relied on a sub-catalogue. This can invalidate a diligent search and therefore expose the $\mathrm{CHI}$ to infringement claims.

As the discussion has shown, the accessibility of work types varies by jurisdiction. In the UK, accessibility does not significantly vary according to work types. Instead the search burden is largely determined by the number of sources. In the Netherlands, freely accessible sources are comparable across work types, except for audio-visual works. Here, access is generally more restricted and in particular a higher percentage of sources requires direct contact with the organisation. In Italy, variations are also limited in that a comparable percentage of sources are freely accessible. However, fully restricted and partial online access is a particularly acute challenge for visual works.

\section{Conclusions}

This paper has analysed the legal requirements for carrying out a diligent search in three countries: the United Kingdom, the Netherlands, and Italy. The focus was on two distinct but interrelated aspects of the search as relevant to CHIs: (1) how Member States strike a balance between legal certainty and flexibility; and (2) how burdensome the diligent search requirement is in practice.

This article has demonstrated that the UK provides the highest legal certainty to CHIs carrying out a diligent search. It provides for extensive guidance, listing specific sources that need to be consulted according to work types. Nonetheless, absolute certainty is not achieved as the list is open-ended. However, the detailed nature of the list helps CHIs not to miss relevant sources. One issue though is the lack of a hierarchy in the sources and the actual almost exhaustive nature of the list. In practice, "diligent" is interpreted by the UKIPO as meaning "exhaustive". The result is that a large number of sources needs to be searched. In fact, a CHI carrying out a mass digitisation project could not feasibly search that many sources for each work, with its limited resources. This situation is also not facilitated by the accessibility of the sources. The data show that little more than half of the sources listed for a diligent search are freely accessible online. The findings regarding the accessibility of sources by type of work among the examined three countries are mostly consistent, with books and images being the most accessible, while unpublished works are more difficult to trace.

Italy has chosen a middle way, although more by bureaucratic need rather than intent. It currently provides some guidance on the key sources that need to be consulted but the advice is not definitive. It therefore essentially provides the important sources but is not detailed enough to legally guarantee the CHIs that these sources will be sufficient. Compared to the UK, Italy has thus favoured a flexible approach. The result is that fewer sources need to be considered compulsory. However, in the absence of definite choices, a CHI still needs to consult a large number of sources per work. Most notably, the delays affecting the national databases of orphan works are proving a major hold-up. Furthermore, a large percentage of sources is not freely accessible online, which in turn significantly increases the search burden. This is especially relevant as even the mandatory ones 
fall into this category. Another particular issue in this context are sources that can only be partially searched online. This poses the risk that a search is incomplete. A CHI may think it searched the full catalogue but instead only searched a part of it, negatively affecting legal certainty. Overall, therefore, the Italian approach to legal certainty produces fewer sources that need to be consulted for a search to be considered diligent. Having said this, the numbers are still large and their limited accessibility makes the search more onerous than the numbers may suggest.

The Netherlands has taken an entirely different approach compared to Italy and especially the UK. It has in effect chosen flexibility over legal certainty by only providing for general categories of sources that need to be consulted, with the exception of the legal deposit which is part of the National Library's catalogue and Sound and Vision's archive. There is no further guidance available beyond this. The result is that CHIs need to decide what sources to consult as relevant and how far to carry the search. The meaning of the term "diligent" is therefore essentially determined in-house, based on a risk assessment. This can trigger an overly cautious approach in practice. At the same time, even an extensive search in the Netherlands is less burdensome than in the UK or Italy in terms of the numbers of sources that need to be consulted. However, the lack of online access to the key sources is very conspicuous here, raising the practical costs significantly. This is only partially remedied by the presence of ECL schemes which do not require this kind of search, but do not extend to all works covered in the Directive.

In all three jurisdictions examined here the number of sources to be searched is too large to make the OWD an effective tool for CHIs involved in mass digitisation projects. This means that the main issues faced by the CHIs are the large number of sources and the fact that the major ones are not freely accessible online. A possible solution to this problem might involve legislative action, official guidelines or jurisprudence to establish hierarchies among the sources for a diligent search, with a diversification between compulsory and optional sources, depending on their relevance and accessibility. Ideally, only freely accessible sources should be considered mandatory for a diligent search. In other words, a diligent search must be considered as carried out in good faith if all relevant freely and easily accessible sources have been consulted. Guidance incorporating this principle should be issued at EU and national level. In addition, given the large number of sources that is deemed relevant, central search tools should be developed. This would allow the CHIs to reduce the search burden by consulting more than one database at a time.

Open Access This article is distributed under the terms of the Creative Commons Attribution 4.0 International License (http://creativecommons.org/licenses/by/4.0/), which permits unrestricted use, distribution, and reproduction in any medium, provided you give appropriate credit to the original author(s) and the source, provide a link to the Creative Commons license, and indicate if changes were made.

\section{References}

Angelopoulos A (2012) The myth of term harmonisation: 27 public domains for 27 member states. Int Rev Intellect Prop Compet Law 35(5):567-594

Beunen A (2011) Gezamenlijke reactie van Nederlandse erfgoedinstellingen op de consultatie over het Europese Richtlijnvoorstel Verweesde Werken. Available at: https://www.internetconsultatie.nl/ verweesde_werken/reactie/6098/bestand. Accessed 11 June 2016 
Kraai HG (2011) Reactie van het Nationaal Archief t.b.v internetconsultatie Richtlijnvoorstel Verweesde Werken. Available at: https://www.internetconsultatie.nl/verweesde_werken/reactie/6084/bestand. Accessed 11 Jan 2016

Leva F (2015) Dalle opere orfane, un nuovo ruolo delle biblioteche per il pubblico dominio e l'utilità sociale. DigItalia 2:9

van Nispen AGCM (2011) Reactie NL Internetconsultatie verweesde werken-Stichting DEN en de richtlijn. Available at: https://www.internetconsultatie.nl/verweesde_werken/reactie/6094/bestand. Accessed 11 Jan 2016 